\title{
Aerosol emission is increased in professional singing
}

Dirk Mürbe ${ }^{1, *,+}$, Martin Kriegel $^{2,+}$, Julia Lange $^{2}$, Hansjörg Rotheudt ${ }^{2}$, and Mario Fleischer ${ }^{1}$

4

In this study, emission rates of aerosols emitted by professional singers were measured with a laser particle counter under cleanroom conditions. The emission rates during singing varied between 753.4 and $6095.37 \mathrm{P} / \mathrm{s}$. Emission rates for singing were compared with data for breathing and speaking. Significantly higher emission rates were found for singing. The growth rates between singing and speaking were between 3.97 and 99.54. Further, effects of vocal loudness and gender were investigated. The present study should support the efforts to improve the risk management in cases of possible aerogenic virus transmission, especially for choir singing.

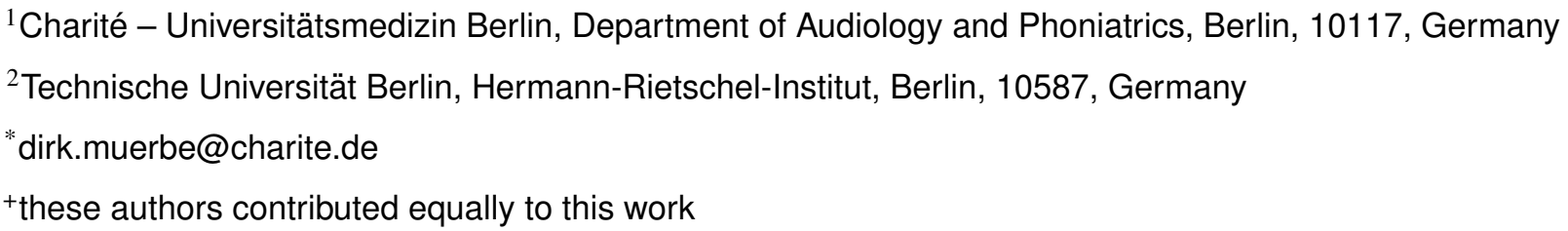

\section{ABSTRACT}

\section{Introduction}

The respiratory system is the main transmission route for SARS-CoV-2-viruses ${ }^{1,2}$.

Depending on particle size, a distinction can be made between droplets with a diameter greater than $5 \mu \mathrm{m}$ and particles smaller than $5 \mu \mathrm{m}$ (aerosols or droplet nuclei) ${ }^{3-5}$. Droplets and aerosols differ according to the influence of gravity. For example, droplets of a size of $100 \mu \mathrm{m}$ sink to the ground within a short time and are transported up to a distance of $1.5 \mathrm{~m}^{6,7}$.

When aerosols are exhaled, the fluid component of the pathogen-containing particles evaporates more and more. They become lighter, can float in the air for longer periods and spread in closed rooms by air flow and diffusion ${ }^{8}$. As the basis of a possible aerogenic transmission of the SARS-CoV-2-virus, the spatial distribution of aerosols is dependent on several factors of the surrounding air, such as temperature and humidity ${ }^{9}$.

Droplets and aerosols are also produced during speaking and singing, because the respiratory tract 
has a dual function: it is not only the main tool for ventilation, but also the source of voice and spoken language production. Particle formation in the pulmonary alveoli ${ }^{10}$, flow effects of the vibrating vocal folds and adjustments of the articulation instruments are regarded as aerosol generating mechanisms ${ }^{11}$.

In comparison to breathing, a stronger formation of aerosols is known for speaking, whereby also a dependence of the number of the arising particles on vocal loudness is described ${ }^{12,13}$. For singing, a significantly higher aerosol production is assumed, probably due to the underlying physiological mechanisms and the greater continuity of voice production over time. This assumption is supported by reports of high infection rates during choir rehearsals in closed rooms ${ }^{14}$.

Previous measurements focus on fluid mechanical aspects in the near-field plume of the mouth during singing 6,15 . The spread of the emitted droplets is investigated, hence distance rules can be derived for protection against droplet infection. However, a risk assessment including the distribution of aerosols in larger rooms is not possible with this method.

The current investigations aim to initially determine the number and size distribution of even small particles emitted in the room by professional singers during singing. This information can be the basis for a numerical calculation of the distribution of aerosols in larger rooms, which takes into account the boundary conditions being typical for concert and opera performances.

The present data may contribute to improved risk management strategies in the fields of culture and education. They should be used for specification of hygiene measures and ventilation concepts in order to facilitate performances and events.

\section{Results}

\section{Particle size distribution}

The particle count measurement method detects different sizes of particles from $0.3 \mu \mathrm{m}$ to $25 \mu \mathrm{m}$. As shown in the log-probability plot (Fig. 1), $>99 \%$ of all detected particles were $\leq 5 \mu \mathrm{m}(>80 \%$ of all particles $\leq 1 \mu \mathrm{m})$. Based on this observation, and following the agreement that aerosol particles of size $\leq 5 \mu \mathrm{m}$ are referred to as aerosol particles, the following results are given for particles of size $0.3 \mu \mathrm{m}-$ $5 \mu \mathrm{m}$.

\section{Experiment I}

Figure 2 illustrates both the emission rates for the different test conditions (breathing, speaking, and singing) and the maximum sound pressure levels for singing. 
The results confirm the hypothesis of higher emission rates for singing compared to breathing and speaking.

While the individual median values for singing ranged from $753.36 \mathrm{P} / \mathrm{s}$ (S5) to $6095.37 \mathrm{P} / \mathrm{s}(\mathrm{S} 2)$ (Table 1), those for speaking ranged from $14.13 \mathrm{P} / \mathrm{s}$ (S6) to $390.84 \mathrm{P} / \mathrm{s}$ (S1) (Table 1). The individual median values for breathing ranged from $4.71 \mathrm{P} / \mathrm{s}$ (S1) to 428.55 (S2) (Table 1).

The growth rate of the emission rates for singing in comparison to speaking was between 3.97 (S1) and 99.54 (S2). Moreover, the growth rate of the emission rates for singing in comparison to breathing was between 14.22 (S2) and 329.61 (S1) (Table 2).

The evaluation of the sound pressure levels showed that the higher voice classifications soprano (female) and tenor (male) had the expected higher sound pressure levels than the lower voice classifications alto and baritone. While the maximum sound pressure level of males in the selected sample were always positively correlated with the particle emission rate, there was no clear correlation in this respect for the female voices.

Statistical analysis by means of linear mixed modeling (Equation 2) showed significant differences of the (logarithmic) emission rate $\log _{10} P_{M}$ between the different test conditions breathing, speaking and singing. Condition affected $\log _{10} P_{M}\left(\chi^{2}(2)=37.797, \mathrm{p}=6.2 \cdot 10^{-9}\right)$ increasing it by a factor of $0.5230 \pm 0.2664$ (standard errors) from breathing to speaking and by a factor of $1.7740 \pm 0.1211$ (standard errors) from breathing to singing. By-subject analysis turned out that S2 and S6 showed a decrease of emitted particles from breathing to speaking (see Fig. 2).

Further, female singers showed significantly higher emission rates than males. Gender affected $\log _{10} P_{M}$ $\left(\chi^{2}(1)=4.3035, \mathrm{p}=0.03803\right)$ lowering it by a factor of $-0.3453 \pm 0.1246$ (standard errors) from female to male.

\section{Experiment II}

The results of measurements with the sustained vowel /a/ at different loudness conditions are presented in Fig. 3. Seven of the eight subjects showed an increase in the emission rate with increasing loudness. The comparison of piano (Table 3) and forte (Table 3) showed a growth rate up to 114.29 (S3) (Table 2). There were higher emission rates for singing in forte for females (from $2023.02 \mathrm{P} / \mathrm{s}$ (S1) to $8072.35 \mathrm{P} / \mathrm{s}$ (S3)) compared to males (from $376.7 \mathrm{P} / \mathrm{s}$ (S5) to $2851.02 \mathrm{P} / \mathrm{s}$ (S7)). The same implications were made during the increase from piano to mezzo-forte (see also Table 2).

Statistical analysis by means of linear mixed modeling (Equation 2) showed significant differences of 
the emission rate $\log _{10} P_{M}$ for the different vocal loudness conditions piano, mezzoforte and forte. Vocal loudness affected $\log _{10} P_{M}\left(\chi^{2}(2)=12.47, \mathrm{p}=0.00196\right)$ lowering it by a factor of $-0.45994 \pm 0.11196$ (standard errors) from forte to mezzoforte and by a factor of $-1.25514 \pm 0.23734$ (standard errors) from forte to piano. The described higher emission rates for females than for males failed to reach statistical significance.

For all subjects, the intended increase in loudness from piano to forte was reflected in the measured values of the sound pressure level. Additionally, Figure 4 shows the relationship between the emission rate and the maximum sound pressure level (only the median values for experiment II - sustained vowel /a/ - were considered). An increase in the sound pressure level was accompanied by a mean increase in the emission rate $\log _{10} P_{M}$ by a factor of 0.06 . With regard to sustained vowels, it could be stated that the emission rates can vary by more than two orders of magnitude.

\section{Discussion}

Due to the increased risk of transmission of SARS-CoV-2 viruses during singing and the described accumulation of these infections during choir rehearsals, the survey of particle emissions and the assessment of aerosols in rooms are key elements in the risk management of ensemble and choir singing in enclosed rooms.

The measuring method used (laser particle counter) provides very high accuracy concerning the absolute number of particles and their size because sources of interference have been reduced to a minimum. Furthermore, the suitability of the peripheral test setup could be proven within the scope of baseline measurements.

An alternative or supplemental method to investigate the size distribution of droplets during breathing, speaking and singing is the imaging technique of Particle Image Velocimetry (PIV). This is based on high-resolution photos of the particles, which are illuminated with a laser light, for example. Studies using PIV also show that more particles are emitted when speaking loudly than speaking with low voice ${ }^{15}$. However, mainly qualitative statements can be made here, due to several influencing factors. Size and number of particles can only be estimated, because of the background concentration of particles in the room and some drops can only be picked up in a blurred way. In a recent study ${ }^{16}$, particles of the sizes 1 , 10, and $100 \mu \mathrm{m}$ were measured with PIV and high accuracy was shown for particles greater than $6 \mu \mathrm{m}$. This may be a reason why investigations of the size distribution of droplets with PIV lead to significantly higher mean particle diameters ${ }^{17}$. Recent studies show that with PIV, particles in the order of $1 \mu \mathrm{m}$ can 
be examined ${ }^{6}$. For particles, in the order of $0.3-20 \mu \mathrm{m}$, the laser particle counter used in cleanroom conditions offers higher accuracy in determining the number and size of particles.

It should be noted, that the relative humidity of about $40 \%$, the initial velocity at the mouth, and constant airflow in the glass pipe lead to biased particle sizes as measured by the laser particle counter.

According to Nicas et al. ${ }^{18}$, particles with an initial diameter of $20 \mu \mathrm{m}$ shrink by a factor of 2 , and according to Wei $\& \mathrm{Li}^{7}$ particles up to $1000 \mu \mathrm{m}$ shrink by a factor of 3 to the equilibrium diameter, nearly independently of the relative humidity in the room.

The size of this final state is dependent on the amount of non-soluble residues, on the humidity, and the residual respiratory fluid. This final state, called droplet nuclei, is what is referred to as a particle in the context of this article.

In contrast, humidity has a highly relevant impact on the evaporation time of droplets. In general, the evaporation time is proportional to the square of the initial diameter ${ }^{7,8}$. Considering the greatest measured particle size of $5 \mu \mathrm{m}$ in this study and a shrinking factor of 3, one gets droplets of a diameter of $15 \mu \mathrm{m}$ in maximum. Whereas a droplet of a size of $15 \mu \mathrm{m}$ in diameter evaporates in dry air in about $0.15 \mathrm{~s}$ to its resting state, the evaporation time increases at a relative humidity of $90 \%$ by a factor of about 25 to $3.75 \mathrm{~s}$ (values were interpolated considering Table 1 in Wei \& $\mathrm{Li}^{7}$ ). More than $80 \%$ of the particles measured in this study are equal to or smaller than $1 \mu \mathrm{m}$ ( $3 \mu \mathrm{m}$ un-evaporated). For this particle size, evaporation times are in the order of $0.006 \mathrm{~s}$ in dry air, and $0.08 \mathrm{~s}$ in moist air.

Considering an initial fluid volume velocity at the mouth opening of about 0.142 (females) to 0.244 (males) liters per seconds for spoken vowels ${ }^{19}$, a lip opening area of about 300 to $1100 \mathrm{~mm}^{2}$ for females ${ }^{20}$ and 214.4 to $830.8 \mathrm{~mm}^{2}$ for males ${ }^{21}$ one gets fluid velocities in maximum in the order of magnitude of 0.47 (females) up to $1.14 \mathrm{~m} / \mathrm{s}$ (males) for sustained vowels. These values are up to one order of magnitude lower than reported values of $2.31-4.07 \mathrm{~m} / \mathrm{s}^{22}$ and $3.9 \mathrm{~m} / \mathrm{s}^{17}$ for speach. Adding these values to the constant fluid flow velocity of $1.63 \mathrm{~m} / \mathrm{s}$ in the glass pipe used in the experiment, droplets dispersed with a velocity of $5.7 \mathrm{~m} / \mathrm{s}$ in maximum over the length of $810 \mathrm{~mm}$ (Fig. 5).

Taking into account the evaporation time of $3.75 \mathrm{~s}$ for $15 \mu \mathrm{m}$ droplets, a characteristic evaporation length of $21.375 \mathrm{~m}$ occurs. This length is lowered for droplets of the size of $3 \mu \mathrm{m}$ to $0.456 \mathrm{~m}$. Assumption of dry air, these values drop considerably to $0.84 \mathrm{~m}$ for $15 \mu \mathrm{m}$ droplets and $0.034 \mathrm{~m}$ for $1 \mu \mathrm{m}$ droplets. Recognizing a relative humidity of about $40 \%$ in the cleanroom, it can be expected that most of the emitted droplets evaporates to droplet nuclei before reaching the laser particle counter. Additionally, because of the small initial size of about $15 \mu \mathrm{m}$ in the maximum of the particles, no dissection is expected and the 
measured number of particles should be correct. To summarize these assessments, it should be noted that the particle sizes measured are recognized as aerosols which distribute in an environment and not as particles that were emitted by a subject directly at the mouth. Thus, the droplet nuclei represent a realistic measure for possible carrier particles for viruses.

Since the aerosols emitted during breathing, speaking ${ }^{12}$ and singing are mainly $<1 \mu \mathrm{m}$ in size, it cannot be assumed that they sink quickly to the ground. It had been shown, that the retention time was in the range of minutes to hours and the sink rate is in the order of $<1 \mathrm{~mm} / \mathrm{s}^{4,7,8}$. The determined order of magnitude of the particle size of this study is significantly lower than the results of the only study, where the particle emission during singing was also investigated. In this former study, the estimated particle size during singing was determined with $68 \mu \mathrm{m}$ in median ${ }^{23,24}$. Furthermore, in the same study, the sizes of the emitted particles for speaking were determined by $81 \mu \mathrm{m}$. Apart from the methodological aspect discussed above, the discrepancy between these and the data presented in this article, is probably due to the high-precision measuring methods not yet available at that time. With regard to the size of emitted particles, one was able to show that they are distinctively smaller than $10 \mu \mathrm{m}$ during speaking and breathing $^{25,26}$.

The present study confirms that higher emission rates of aerosols are produced during singing in comparison to speaking and breathing. A higher emission rate for speaking compared to breathing and an increase of emission rates with raising vocal loudness was found ${ }^{25}$. One could further show that the range of emission rate ranges from 1 to $50 \mathrm{P} / \mathrm{s}_{\text {for }}$ speaking ${ }^{25}$, which roughly confirms our data (14.13 to 390.84, see Table 1). Furthermore, there is a good agreement in the emission rate in breathing ${ }^{25}$.

However, phonation of sustained vowels, characterized by a periodic collision of the vocal folds correlating with pitch, does not reflect the ordinary situation in choral singing. Here, the order of consonants and vowels alternate in a sung passage and are interrupted by pauses. Therefore, in the present study, a sequence of 50 seconds of the choir piece "Abschied vom Walde" by Felix Mendelssohn Bartholdy was selected. Each line of the four-part choral movement was sung by the individually appropriate voice classification (soprano, alto, tenor, baritone). These data were compared with the tasks 'breathing' and 'speaking' (reading the standardized text corpus). Again, there is an increase of the emission rate for singing in comparison to speaking. Probably, this is due to the higher ratio of voiced segments to pauses and the increased sound pressure level in singing. Further, these findings agree with the observation that voiced vocalizations lead to higher aerosol emissions ${ }^{1,13}$.

Apart from the influence of vocal loudness on the emission rate, we found gender differences with 
higher emission rates for female singers. One reason for a stronger aerosol generation might be the higher frequency of the vibrating vocal folds. This counts both, for the higher soprano and alto line of the four-part choral movement and for the selected higher pitch for females during sustained phonation.

However, the data presented here show no clear homogeneity within the cohort. For example, the emission rate determined for singing fluctuates by almost one order of magnitude. Also, the increase of $P_{M}$ between singing and speaking fluctuates by almost two orders of magnitude. Thus, the aspect of high-emitters or super-emitters might be considered ${ }^{25}$.

Of course, the determined emission rate does not provide any information about a possible concentration of SARS-CoV-2 viruses yet. However, at present this number can not serve to estimate the probability of infection ${ }^{27}$.

It should be noted that in the course of the actual pandemic so far, numerous situations seem to be related to a high probability of aerogenic virus transmission, among them choir rehearsals. There is also initial evidence of viable SARS-CoV-2 viruses in indoor air $^{28}$. However, comprehensive information on the transmission quantity and survivability of SARS-CoV-2 viruses in aerosols is still missing ${ }^{29}$.

Therefore, the present study contributes to one component in the risk assessment of singing, which in turn is largely determined by the current prevalence. Finally, there is a lack of data on whether specific breathing characteristics of singing (deep inhalation, higher intrapulmonary pressures) influence the risk of transmission when singing loudly. In any case, the data should support all efforts to improve the risk management, especially in choir singing.

\section{Methods}

\section{Subjects}

Eight singers (ages 22 to 62 years; professional choir experience between 1 to 34 years) of a professional chamber choir (RIAS Kammerchor Berlin) took part in the investigations. To each of the different voice classifications belonged two of the subject group: alto (S1 \& S2), soprano (S3 \& S4), baritone (S5 \& S6), and tenor (S7 \& S8). This study was conducted according to the ethical principles based on the WMA Declaration of Helsinki and to the current legal provisions. It was approved by the ethics committee of the TU Berlin, and informed written consent was obtained from all subjects. It should be noted, that the results for breathing and speaking tasks of the subjects considered in this study, have already been analyzed within a larger cohort ${ }^{12}$. In order to allow a direct comparison with the data for singing, the data 
of this subgroup were reused and analyzed.

\section{Particle measurements}

The investigations were carried out in a cleanroom at the Hermann Rietschel Institute of the Technical University of Berlin.

The supply air was introduced via a vertical low-turbulence displacement flow (TAV) over the entire ceiling area of $4.8 \times 4.8 \mathrm{~m}^{2}$. The supply air velocity was $0.3 \mathrm{~m} / \mathrm{s}$ and thus prevented thermal lift at the people. The exhaust air was also discharged from the room over the entire surface via a raised floor. The room temperature was $295.15 \mathrm{~K} \pm 0.50 \mathrm{~K}$, the relative humidity was $40 \% \pm 2 \%$ and the room had $15 \mathrm{~Pa}$ overpressure to the surrounding rooms.

The actual test stand was located in this highly pure environment (Fig. 5). It consisted of a glass pipe, in which a constant airflow of $400 \mathrm{~m}^{3} / \mathrm{h}$ was generated by a filter fan unit (Ziehl-Abegg, Künzelsau, Deutschland). The measuring probe of a laser particle counter (Lighthouse Solair 3100 E, Lighthouse Worldwide Solutions, Fremont, CA) was placed centrally in the pipe.

The particle counter was counting with a volume flow $\dot{V}_{P C}$ of $28.3 \mathrm{l} / \mathrm{min}$, with a measuring time of 10 seconds each and detected particles in six size classes: $>0.3 \mu \mathrm{m}-0.5 \mu \mathrm{m},>0.5 \mu \mathrm{m}-1.0 \mu \mathrm{m},>1.0 \mu \mathrm{m}-$ $3.0,>3.0 \mu \mathrm{m}-5.0 \mu \mathrm{m},>5.0 \mu \mathrm{m}-10 \mu \mathrm{m}$ and $>10 \mu \mathrm{m}$.

The emission rate $P_{M}$ presented in Figs. 2 - 4 was computed based on the measured particle concentration $c_{M}$ and the volume flow through the filter fan unit (FFU) $\dot{V}_{F F U}$, i.e.

$$
P_{M}=c_{M} \cdot \dot{V}_{F F U}
$$

To estimate sources of interference, such as background noise of particles in the room, as well as abrasion on the clothing and hair of the persons investigated, a baseline measurement was carried out at the beginning of the investigation. For particle reduction due to movement artifacts, the test persons wore cleanroom clothing and a headgear with the sealing of the edges with adhesive tape, so that only eyes, nose, and mouth were uncovered.

In this baseline measurement, a count rate of the particle counter of $<1$ particles $/ 5$ minutes was determined within a measurement period of 10 minutes.

The counting efficiency for particles of the size $0.3 \mu \mathrm{m}$ is $50 \% \pm 20 \%$ and for particles of the size $0.5 \mu \mathrm{m}$ it is $100 \% \pm 10 \%$ according to ISO $21501-4$. To investigate how many particles were separated 
over the measuring distance, comparative measurements were made over a short distance from the particle counter. For this case, the particles were directly collected through a $150 \mathrm{~mm}$ high funnel while breathing and speaking and directed to the particle counter. The same size distribution was found as in the finally used configuration.

\section{Audio measurements}

The sound pressure level was determined using a calibrated sound level meter (CENTER 322_ Datalogger Sound Level Meter, Center Technologies, Houston, TX). During all measurements, the sound level meter was located approximately $60 \mathrm{~cm}$ anterior-laterally away from the mouth of the test persons due to limited accessibility. The measuring arrangement of the particle counter did not allow a standard positioning of $30 \mathrm{~cm}$ mouth distance of the measuring device. Furthermore, the high sensitivity of the particle counter did not allow a frontal positioning of the sound level meter inside the glass tube. Consequently, the determined levels were not to be considered as absolute levels but are lowered by a constant value of approx. $10 \mathrm{~dB}$ SPL.

Due to the time variability of the determined sound pressure levels (primarily for speaking and singing), the maximum value $L_{A F_{M A X}}$ of the frequency- and time-weighted acoustic pressure was recorded and evaluated.

\section{Test conditions}

The subjects were in a sitting position at the entry of the particle measurement setup. Two experiments were carried out:

Experiment I: Comparison of three different test conditions

a) Breathing through the mouth

b) Reading a standardized text

c) Singing a line of a four-part choral movement

Experiment II: Singing a sustained vowel (/a/) at three loudness conditions

a) piano

b) mezzo-forte 
c) forte

For experiment I, respectively, a time window of 50 seconds was analyzed. Further, for experiment II the time window was set to 10 seconds. For reading in a comfortable loudness condition (Ib), the text "Der Nordwind und die Sonne” by Äsop was selected. To pass Ic) the choral part of the song "Abschied vom Walde" by Felix Mendelssohn-Bartholdy was chosen. The subjects were instructed to sing the line of their individual voice classification. Each of all tasks were repeated five times.

The following pitches were selected for experiment II: soprano: C5 (523 Hz), alto: F4 (349 Hz), tenor: C4 $(262 \mathrm{~Hz})$, and baritone: F3 $(175 \mathrm{~Hz})$. The total measuring time for all tasks was about 30 minutes for each subject.

\section{Statistical Analysis}

Besides the description of the data, a confirmative analysis was carried out. Therefore, a linear mixed effects analysis of the relationship between $\log _{10} P_{M}$, gender, condition and subject was performed by means of the freely available software package $R^{30}$ including the package lme $4^{31,32}$. The model used was

$$
\log _{10} P_{M} \sim \text { Condition }+ \text { Gender }+(1+\text { Condition } \mid \text { Subject })+(1+\text { Gender } \mid \text { Subject })
$$

( $\mathrm{R}$ model syntax). Condition and gender were incorporated as fixed effects into the model. Intercepts for subject were incorporated as random effects. To keep the model maximal ${ }^{33}$, by--subject random slopes for the effect of gender and condition were additionally incorporated as random effects. The interaction term between condition and gender was identified as not significant and therefore not regarded. Careful visual inspection of residual-plots and Q-Q-plots did reveal obvious deviations from homoscedasticity and normality. Therefore, log-transform of $P_{M}$ was considered which overcomes these problems. To avoid infinite values in the analyses, only $P_{M}>0$ were taken into account. To test significance, the P-values were obtained by likelihood ratio tests of the full model with the effect in question against the model without the effect in question. For this reason, linear mixed models were fit by maximum likelihood to enable comparison.

\section{References}

1. Asadi, S., Bouvier, N., Wexler, A. S. \& Ristenpart, W. D. The coronavirus pandemic and aerosols: Does covid-19 transmit via expiratory particles? Aerosol Sci. Technol. 54, 635-638, DOI: 10.1080/ 02786826.2020.1749229 (2020). https://doi.org/10.1080/02786826.2020.1749229. 
2. Morawska, L. \& Cao, J. Airborne transmission of sars-cov-2: The world should face the reality. Environ. Int. 105730, DOI: 10.1016/j.envint.2020.105730 (2020).

3. Couch, R. B., Cate, T. R., Douglas, R. G., Gerone, P. J. \& Knight, V. Effect of route of inoculation on experimental respiratory viral disease in volunteers and evidence for airborne transmission. Microbiol. Mol. Biol. Rev. 30, 517-529 (1966). https://mmbr.asm.org/content/30/3/517.full.pdf.

4. Tellier, R. Review of aerosol transmission of influenza a virus. Emerg. infectious diseases 12, 1657-1662 (2006).

5. Judson, S. D. \& Munster, V. J. Nosocomial transmission of emerging viruses via aerosol-generating medical procedures. Viruses 11, 940 (2019).

6. Kähler, C. J. \& Hain, R. Fundamental protective mechanisms of face masks against droplet infections. J. Aerosol Sci. 148, 105617, DOI: https://doi.org/10.1016/j.jaerosci.2020.105617 (2020).

7. Wei, J. \& Li, Y. Enhanced spread of expiratory droplets by turbulence in a cough jet. Build. Environ. 93, 86 - 96, DOI: https://doi.org/10.1016/j.buildenv.2015.06.018 (2015).

8. Stadnytskyi, V., Bax, C. E., Bax, A. \& Anfinrud, P. The airborne lifetime of small speech droplets and their potential importance in sars-cov-2 transmission. Proc. Natl. Acad. Sci. 117, 11875-11877, DOI: 10.1073/pnas.2006874117 (2020). https://www.pnas.org/content/117/22/11875.full.pdf.

9. Morawska, L. Droplet fate in indoor environments, or can we prevent the spread of infection? Indoor Air 16, 335-347, DOI: 10.1111/j.1600-0668.2006.00432.x (2006). https://onlinelibrary.wiley.com/ doi/pdf/10.1111/j.1600-0668.2006.00432.x.

10. Johnson, G. R. \& Morawska, L. The mechanism of breath aerosol formation. J. Aerosol Medicine Pulm. Drug Deliv. 22, 229-237, DOI: 10.1089/jamp.2008.0720 (2009).

11. Johnson, G. et al. Modality of human expired aerosol size distributions. J. Aerosol Sci. 42, 839-851, DOI: 10.1016/j.jaerosci.2011.07.009 (2011).

12. Hartmann, A., Lange, J., Rotheudt, H. \& Kriegel, M. Emission rate and particle size of bioaerosols during breathing, speaking and coughing (2020). DOI: 10.14279/depositonce-10331. Preprint Technische Universität Berlin.

13. Asadi, S. et al. Effect of voicing and articulation manner on aerosol particle emission during human speech. PLOS ONE 15, 1-15, DOI: 10.1371/journal.pone.0227699 (2020). 
14. Hamner, L. et al. High sars-cov-2 attack rate following exposure at a choir practice - skagit county, washington, march 2020. MMWR Morb Mortal Wkly Rep 69, 606-610, DOI: 10.15585/mmwr. mm6919e6 (2020).

15. Anfinrud, P., Stadnytskyi, V., Bax, C. E. \& Bax, A. Visualizing speech-generated oral fluid droplets with laser light scattering. New Engl. J. Medicine DOI: 10.1056/NEJMc2007800 (2020). https: //www.nejm.org/doi/pdf/10.1056/NEJMc2007800.

16. Chen-Yu, C., Atkinson Joseph, F., VanBenschoten John, E., Bursik Marcus, I. \& DePinto Joseph, V. Image-based system for particle counting and sizing. J. Environ. Eng. 126, 258-266, DOI: 10.1061/(asce)0733-9372(2000)126:3(258) (2000).

17. Chao, C. et al. Characterization of expiration air jets and droplet size distributions immediately at the mouth opening. J. Aerosol Sci. 40, 122 - 133, DOI: https://doi.org/10.1016/j.jaerosci.2008.10.003 (2009).

18. Nicas, M., Nazaroff, W. W. \& Hubbard, A. Toward understanding the risk of secondary airborne infection: emission of respirable pathogens. J. occupational environmental hygiene 2, 143-154 (2005).

19. Jiang, J. J., Hanna, R. B., Willey, M. V. \& Rieves, A. The measurement of airflow using singing helmet that allows free movement of the jaw. J. Voice 30, 641-648 (2016).

20. Garnier, M., Henrich, N., Smith, J. \& Wolfe, J. Vocal tract adjustments in the high soprano range. The J. Acoust. Soc. Am. 127, 3771-3780 (2010).

21. Fleischer, M., Pinkert, S., Mattheus, W., Mainka, A. \& Mürbe, D. Formant frequencies and bandwidths of the vocal tract transfer function are affected by the mechanical impedance of the vocal tract wall. Biomech Mod Mechanobiol 14, 719-733 (2015).

22. Kwon, S.-B. et al. Study on the initial velocity distribution of exhaled air from coughing and speaking. Chemosphere 87, 1260-1264 (2012).

23. Loudon, R. G. \& Roberts, R. M. Relation between the airborne diameters of respiratory droplets and the diameter of the stains left after recovery. Nature 213, 95-96 (1967).

24. Loudon, R. G. \& Roberts, R. M. Singing and the dissemination of tuberculosis. Am. Rev. Respir. Dis. 98, 297-300, DOI: 10.1164/arrd.1968.98.2.297 (1968). PMID: 5667756, https://www.atsjournals.org/ doi/pdf/10.1164/arrd.1968.98.2.297. 
25. Asadi, S. et al. Aerosol emission and superemission during human speech increase with voice loudness. Sci. Reports 9, 2348- (2019).

26. Papineni, R. S. \& Rosenthal, F. S. The size distribution of droplets in the exhaled breath of healthy human subjects. J. Aerosol Medicine 10, 105-116, DOI: 10.1089/jam.1997.10.105 (1997). PMID: 10168531, https://doi.org/10.1089/jam.1997.10.105.

27. Bar-On, Y. M., Flamholz, A., Phillips, R. \& Milo, R. Science forum: Sars-cov-2 (covid-19) by the numbers. Elife 9, e57309, DOI: 10.7554/eLife.57309 (2020).

28. Guo, Z.-D. et al. Aerosol and surface distribution of severe acute respiratory syndrome coronavirus 2 in hospital wards, wuhan, china, 2020. Emerg. Infect. Dis. journal 26, 1583 (2020).

29. van Doremalen, N. et al. Aerosol and surface stability of sars-cov-2 as compared with sars-cov-1. New Engl. J. Medicine 382, 1564-1567, DOI: 10.1056/NEJMc2004973 (2020). https://doi.org/10. 1056/NEJMc2004973.

30. R Core Team. R: A Language and Environment for Statistical Computing. R Foundation for Statistical Computing, Vienna, Austria (2020).

31. Bates, D., Mächler, M., Bolker, B. \& Walker, S. Fitting linear mixed-effects models using lme4. J. Stat. Softw. 67, 1-48, DOI: 10.18637/jss.v067.i01 (2015).

32. Winter, B. Linear models and linear mixed effects models in $r$ with linguistic applications (2013). 1308.5499 .

33. Barr, D. J., Levy, R., Scheepers, C. \& Tily, H. J. Random effects structure in mixed-effects models: Keep it maximal. J. Mem. Lang. 68, 255-278 (2013).

\section{Acknowledgements}

We thank the members of the RIAS Kammerchor Berlin for their support.

\section{Author contributions statement}

D. M., M. F., and M. K. designed research. J. L., H. R. and M. F. made measurements. M. F., J. L., D. M. and M. K. wrote the paper. 


\section{${ }_{361}$ Additional information}

362 The authors declare no competing interest. 


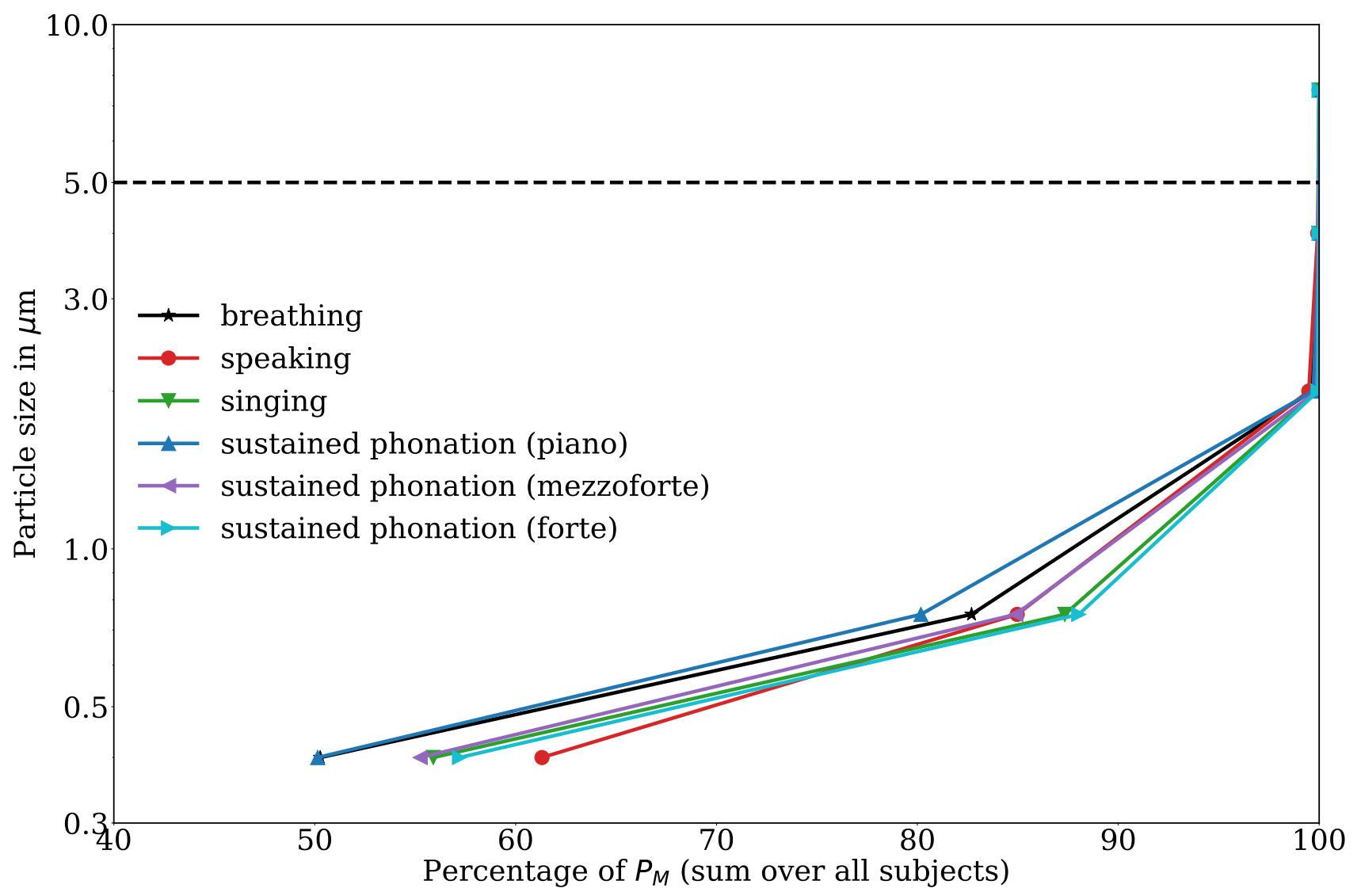

Figure 1. Log-probability plot of the frequency distribution of the size of the detected particles. Regardless of the task, $>99 \%$ of all detected particles are $\leq 5 \mu \mathrm{m}$ (dashed line). Furthermore all tasks show that $>80 \%$ of all particles are $\leq 1 \mu \mathrm{m}$. 


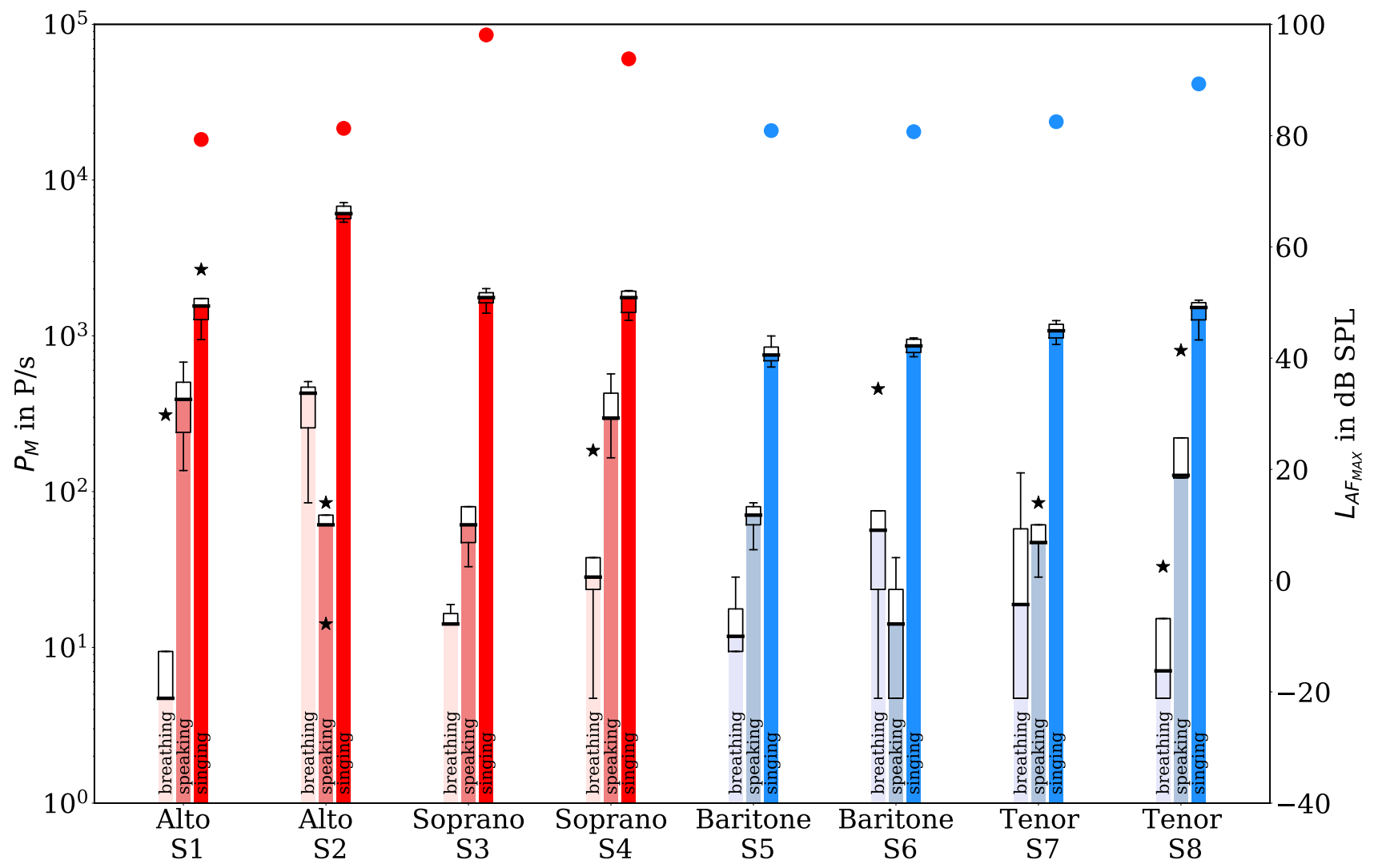

Figure 2. Boxplots of the emission rates (bars represent the median) for different gender, voice classifications and the test conditions breathing, speaking and singing in experiment I (left y-axis). Only particles $\leq 5 \mu \mathrm{m}$ were considered. For singing, the maximum sound pressure levels $\mathrm{LAF}_{\mathrm{MAX}}$ are also shown (full circles, right y-axis). 


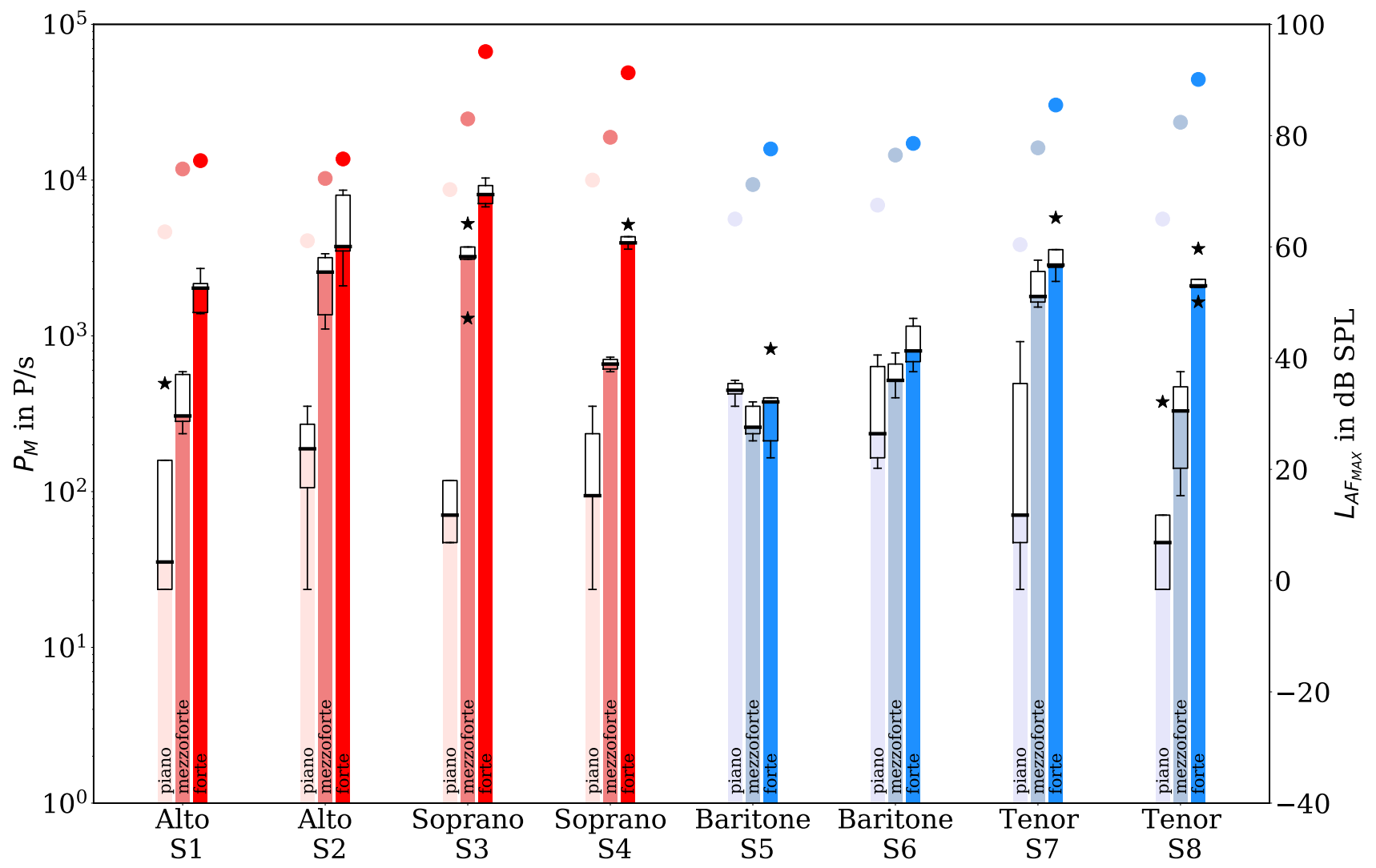

Figure 3. Boxplots of the emission rates (bar represents the median) for different gender, voice classifications and vocal loudness conditions while sustaining the vowel /a/ (Experiment II) (left y-axis). Only particles $\leq 5 \mu \mathrm{m}$ were considered. For the different loudness conditions, the maximum sound pressure levels LAF $\mathrm{MAX}$ are also shown (full circles, right y-axis). 


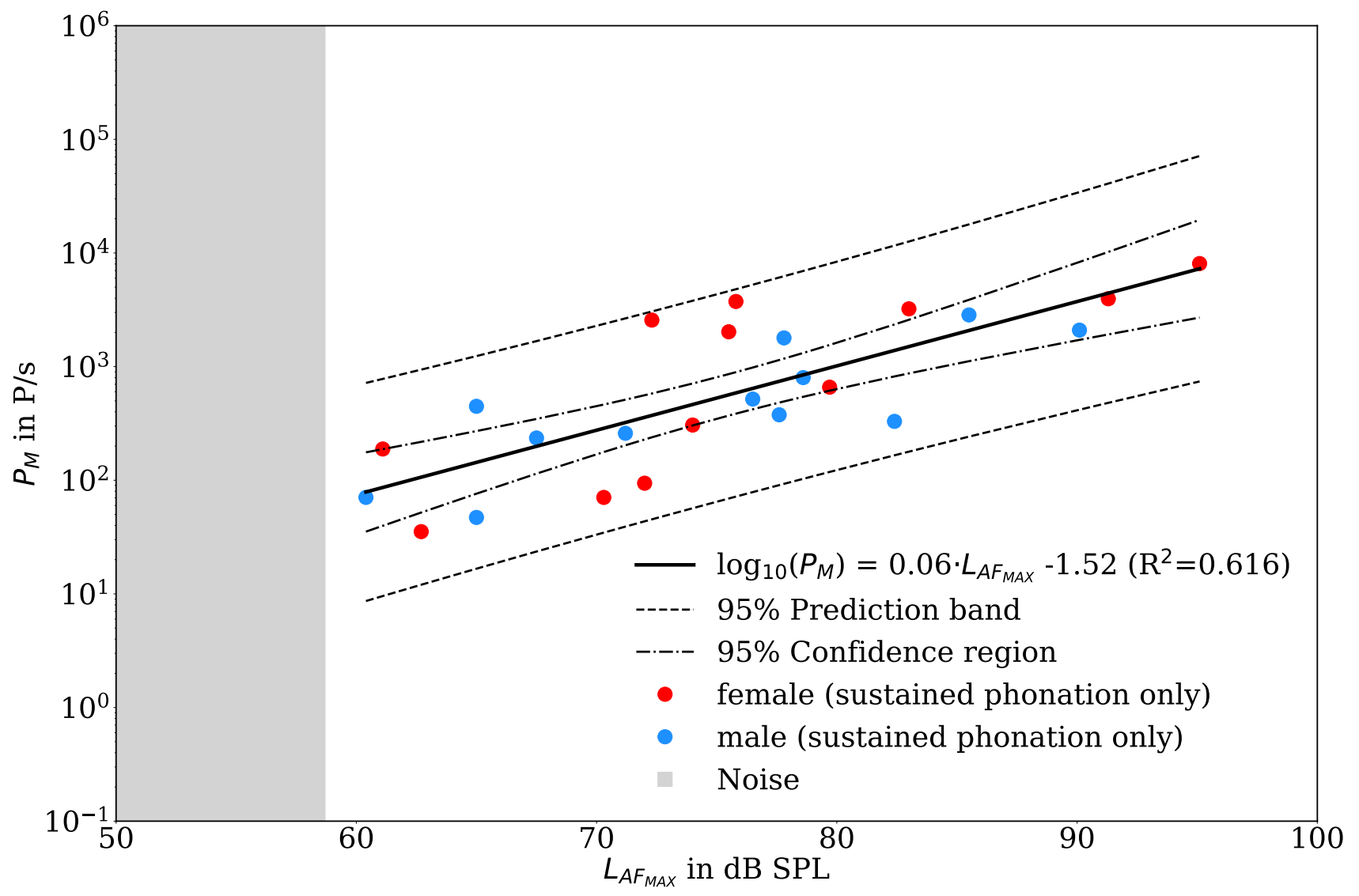

Figure 4. Relationship between emission rate and the maximum sound pressure level for the test condition of sustained vowel /a/ (Experiment II) for all three loudness conditions separated by gender including linear regression of the logarithmic emission rates (black line). Only particles $\leq 5 \mu \mathrm{m}$ were considered. The grey field represents the sound pressure level resulting from the environmental conditions (primarily particle counter) alone. 


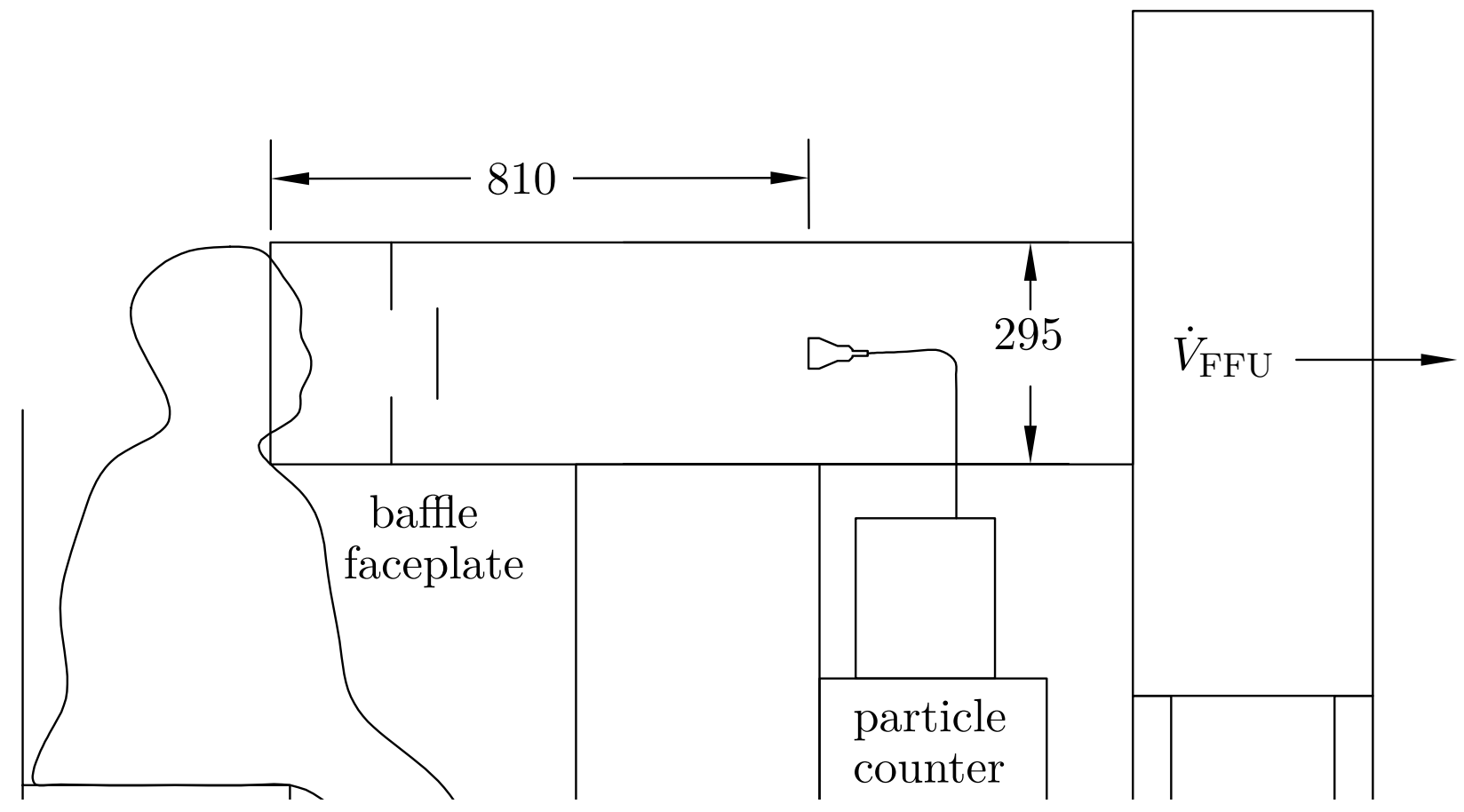

Figure 5. Left: Schematic test setup with one person in cleanroom clothing whose exhaled air was recorded by the particle counter. The glass measuring section was located on the suction side of a horizontally positioned Filter Fan Unit (FFU). All geometric dimensions are in mm (Figure adapted from Fig 2 in Hartmann et al. ${ }^{12}$ ). 
Table 1. Minimum, maximum, and median values of emission rates in $\mathrm{P} / \mathrm{s}$ for breathing, speaking, and singing

\begin{tabular}{c|ccc|ccc|ccc} 
& \multicolumn{3}{|c}{ breathing } & \multicolumn{3}{c}{ speaking } \\
\hline ID & Min & Median & Max & Min & Median & Max & Min & Median & Max \\
\hline S1 & 4.71 & 4.71 & 310.46 & 136.46 & 390.84 & 677.64 & 946.24 & 1552.39 & 2666.86 \\
S2 & 84.72 & 428.55 & 508.16 & 14.13 & 61.24 & 84.72 & 5370.32 & 6095.37 & 7177.94 \\
S3 & 14.13 & 14.13 & 18.84 & 32.96 & 61.24 & 79.98 & 1399.59 & 1761.98 & 2009.09 \\
S4 & 4.71 & 28.25 & 183.65 & 164.82 & 296.48 & 570.16 & 1256.03 & 1761.98 & 1954.34 \\
S5 & 9.42 & 11.53 & 28.25 & 42.36 & 70.63 & 84.72 & 630.96 & 753.36 & 997.70 \\
S6 & 4.71 & 56.49 & 457.09 & 4.71 & 14.13 & 37.67 & 734.51 & 860.99 & 970.51 \\
S7 & 4.71 & 12.47 & 131.83 & 28.25 & 47.10 & 84.72 & 881.05 & 1078.95 & 1253.14 \\
S8 & 4.71 & 6.67 & 32.96 & 122.46 & 127.06 & 805.38 & 941.89 & 1520.55 & 1694.34 \\
\hline
\end{tabular}

Table 2. Ratios of medians of emission rates for different test and loudness conditions

\begin{tabular}{lrrrrr}
\hline ID & Speaking/breathing & Singing/breathing & Singing/speaking & Forte/piano & Forte/mezzoforte \\
\hline S1 & 82.99 & 329.61 & 3.97 & 60.81 & 6.61 \\
S2 & 0.14 & 14.22 & 99.54 & 19.86 & 1.46 \\
S3 & 4.34 & 124.74 & 28.77 & 114.29 & 2.50 \\
S4 & 10.50 & 62.37 & 5.94 & 41.98 & 6.00 \\
S5 & 6.12 & 65.31 & 10.67 & 0.84 & 1.46 \\
S6 & 0.25 & 15.24 & 60.95 & 3.40 & 1.55 \\
S7 & 3.78 & 86.50 & 22.91 & 40.36 & 1.59 \\
S8 & 19.05 & 228.03 & 11.97 & 44.46 & 6.35 \\
\hline
\end{tabular}


Table 3. Minimum, maximum, and median values of emission rates in $\mathrm{P} / \mathrm{s}$ for piano, mezzoforte, and forte

\begin{tabular}{c|ccc|ccc|ccc} 
& \multicolumn{3}{|c}{ piano } & \multicolumn{3}{c}{ mezzoforte } & forte \\
\hline ID & Min & Median & Max & Min & Median & Max & Min & Median & Max \\
\hline S1 & 23.55 & 33.27 & 494.31 & 235.50 & 306.20 & 588.84 & 1389.95 & 2023.02 & 2710.19 \\
S2 & 23.55 & 188.36 & 353.18 & 1106.62 & 2564.48 & 3365.12 & 2094.11 & 3741.11 & 8609.94 \\
S3 & 47.10 & 70.63 & 117.76 & 1294.20 & 3228.49 & 5248.07 & 6729.77 & 8072.35 & 10303.86 \\
S4 & 23.55 & 94.19 & 353.18 & 588.84 & 659.17 & 729.46 & 3605.79 & 3953.67 & 5176.07 \\
S5 & 353.18 & 447.71 & 517.61 & 211.84 & 258.82 & 376.70 & 164.82 & 376.70 & 824.14 \\
S6 & 141.25 & 235.50 & 753.36 & 399.94 & 517.61 & 776.25 & 588.84 & 799.83 & 1294.20 \\
S7 & 23.55 & 70.63 & 918.33 & 1531.09 & 1790.61 & 3061.96 & 2238.72 & 2851.02 & 5714.79 \\
S8 & 23.55 & 47.10 & 376.70 & 94.19 & 329.61 & 588.84 & 1648.16 & 2094.11 & 3622.43 \\
\hline
\end{tabular}

